\title{
Population Pharmacokinetic/Pharmacodynamic Analysis of the DPP-4 Inhibitor Linagliptin in Japanese Patients with Type 2 Diabetes Mellitus
}

\author{
Yusuke Tadayasu ${ }^{1,3}$, Akiko Sarashina ${ }^{1}$, Yasuhiro Tsuda ${ }^{1}$, Shinji Tatami ${ }^{1}$, Christian Friedrich ${ }^{2}$, Silke Retlich ${ }^{2}$, Alexander \\ $\mathrm{Staab}^{2}$, Mikihisa Takano ${ }^{4}$ \\ ${ }^{1}$ Clinical PK/PD, Translational medicine, Nippon Boehringer Ingelheim Co., Ltd, Kobe, Hyogo, Japan. ${ }^{2}$ Translational \\ medicine, Boehringer Ingelheim GmbH \& Co. KG, Biberach, Germany. ${ }^{3}$ Graduate School of Biomedical Sciences, \\ Hiroshima University, Hiroshima, Japan. ${ }^{4}$ Graduate School of Biomedical \& Health Sciences, Hiroshima University, \\ Hiroshima, Japan.
}

Received, August 20, 2013; Revised, December 3, 2013; Accepted, December 9, 2013; Published, December 10, 2013.

\begin{abstract}
Objectives] Linagliptin is a novel, highly selective and long acting DPP-4 inhibitor for the treatment of type 2 diabetes mellitus (T2DM). Linagliptin exhibits non-linear pharmacokinetics (PK) due to saturable binding to plasma and tissue DPP-4. The aim of this study was to characterize the PK and PK/DPP4 inhibition relationship of linagliptin in Japanese patients with T2DM using a population PK/DPP-4 model and to support the rationale for the therapeutic dose in Japanese patients by simulation. [Methods] Linagliptin plasma concentration and DPP-4 inhibition measurements from a placebo-controlled, parallel group multiple (28 days) dose trial that included $36 \mathrm{~T} 2 \mathrm{DM}$ patients (18 patients each in $2.5 \mathrm{mg}$ and $10 \mathrm{mg}$ dose group) were used for analysis. Modeling was performed using FOCE INTERACTION estimation method implemented in NONMEM V. The linagliptin plasma concentration- and DPP-4 inhibition- time profiles were simulated for Japanese patients receiving $5 \mathrm{mg}$ linagliptin once daily by the model established. [Results] Nonlinear PK of linagliptin in T2DM patients were well described by a 2-compartment model assuming concentrationdependent binding to DPP-4 in the central and peripheral compartment. Plasma DPP-4 inhibition was integrated in the model by relating the model-predicted DPP-4 occupancy with linagliptin linearly to DPP-4 inhibition. The simulation predicted that for the $5 \mathrm{mg}$ dose group the trough DPP-4 inhibition at steady-state was $84.2 \%$, which is higher than the target inhibition $(\geq 80 \%)$ for an effective dose of DPP-4 inhibitor. In 2.5 mg dose group, steady-state DPP-4 inhibition of $>80 \%$ was not maintained over 24 hours (observed and simulated). [Conclusions] The nonlinear PK of linagliptin and its plasma DPP-4 inhibition in patients were well characterized by a target-mediated drug disposition model relating DPP-4 occupancy with linagliptin to DPP-4 inhibition. Simulations of plasma DPP-4 inhibition suggest that $5 \mathrm{mg}$ linagliptin once daily is an appropriate therapeutic dose for Japanese patients with T2DM.
\end{abstract}

This article is open to POST-PUBLICATION REVIEW. Registered readers (see "For Readers") may comment by clicking on ABSTRACT on the issue's contents page.

\section{INTRODUCTION}

Linagliptin is a dipeptidyl peptidase (DPP) -4 inhibitor which is licensed in the US, Europe, and Japan for the indication of long term improvement of glycaemic control in patients with type 2 diabetes mellitus (T2DM). The inhibition of DPP-4 leads to an increase of the incretins glucagon-like peptide 1 (GLP-1) and gastric inhibitory polypeptide (GIP), which are substrates of DPP-4. Incretins are secreted in the intestine in response to food intake. Active GLP-1 and GIP act by enhancing insulin secretion [1] and in the case of GLP-1 also by inhibiting glucagon secretion in a glucose dependent way [2]. Both mechanisms lead to lower plasma glucose levels. Moreover, the incretins have protective effects on pancreatic ß-cells by enhancing their proliferation and increasing their resistance to apoptosis in animals [3]. Other beneficial aspects of GLP-1 are the slowing of gastric emptying and the induction of satiety, supporting dietary goals in diabetes treatment. As DPP-4 inhibitors prevent the degradation of incretins by DPP-4, they can elevate the beneficial effects of these regulatory peptides for type 2 diabetic patients. Decreased incretin levels have in fact been reported for diabetic patients [4].

Corresponding Author: Yusuke Tadayasu; Nippon Boehringer Ingelheim Co., Ltd. 6-7-5, Minatojima-Minamimachi; Chuo-ku, Kobe, Hyogo; Japan. E-mail: yusuke.tadayasu@boehringeringelheim.com. 
DPP-4 inhibitors have been shown to alleviate this deficiency and reduce glucose and $\mathrm{HbA1c}$ successfully.

In clinical trial in non-Japanese patients [5], linagliptin exhibits nonlinear pharmacokinetics in the dose range of 1 to $10 \mathrm{mg}$ once daily. The nonlinearity is characterized by a less than dose proportional increase in maximum plasma concentrations $\left(\mathrm{C}_{\max }\right)$ and area under the curve (AUC) [5]. Apparent clearance and apparent volume of distribution increase with increasing dose [5]. Linagliptin exhibited a long-terminal half-life $(>100$ hours at steady state after multiple oral doses of 5 $\mathrm{mg}$ ) but the accumulation half-life is considered to be short (approximately 10 hours with $5 \mathrm{mg}$ dosing), based on a low accumulation ratio (1.33 for AUC and $\mathrm{C}_{\max }$ ) [5]. Urinary excretion was low $(<7 \%$ of dose) with $5 \mathrm{mg}$ dosing. The urinary excretion of linagliptin increased with increasing dose [5].

Linagliptin treatment resulted in a rapid, potent and long-lasting inhibition of plasma DPP-4 in clinical trials, and linagliptin plasma concentrations correlated well with DPP-4 activity measured in plasma, without hysteresis. DPP-4 was effectively inhibited as shown by maximum DPP-4 inhibitions of 72.7 and $86.1 \%$ after a single dose of linagliptin of 2.5 and $5 \mathrm{mg}$, respectively, and $>95 \%$ for doses of $\geq 25 \mathrm{mg}$ [6]. At steady-state, inhibition $\geq 80 \%$ of plasma DPP-4 activity for at least 24 hours post dose was achieved with $5 \mathrm{mg}$ and $10 \mathrm{mg}$ linagliptin once daily dosing [5]. Generally, DPP-4 inhibition $\geq 80 \%$ over $24 \mathrm{~h}$ is thought to be therapeutically necessary, as this was shown to be related to maximum effects in terms of incretin response and glucose reduction $[7,8]$.

An in vitro protein binding study performed with radiolabelled linagliptin demonstrated that the bound fraction of linagliptin decreased from $99 \%$ at concentrations of $\leq 1 \mathrm{nmol} / \mathrm{L}$ to 70 to $80 \%$ at concentrations $>100 \mathrm{nmol} / \mathrm{L}$ [9]. The binding of linagliptin to plasma protein was associated with very high affinity constants (in the order of $10^{10}$ $\mathrm{L} / \mathrm{mol}$ ). In contrast, protein binding was not concentration-dependent in plasma from DPP-4 deficient or knock-out animals, with approximately $70 \%$ of linagliptin bound to plasma protein [9]. In line with these observations, the DPP-4 deficient or knock-out animals showed approximately linear pharmacokinetics of linagliptin in the relevant dose range [10]. Based on these findings, the nonlinear pharmacokinetics of linagliptin can be explained predominantly by a high affinity, low capacity binding to its target enzyme DPP-4, which is readily saturated at therapeutically relevant concentration.
The target-mediated drug disposition has also been described for angiotensin I converting enzyme inhibitors such as trandolaprilat, which shows similar pharmacokinetic characteristics as linagliptin [11].

The approved dose of linagliptin is $5 \mathrm{mg}$ once daily in US, Europe, and Japan. In a Phase III trial in Japanese with T2DM $[12,13], 5$ and $10 \mathrm{mg}$ once daily were tested. However, in the Phase II trial in Japanese patients with T2DM [14], linagliptin doses of $0.5,2.5,10 \mathrm{mg}$ once daily, but not $5 \mathrm{mg}$, were administered. From the perspective of the practical efficiency, these 3 doses were selected to investigate the dose response in the wider range than in the precedent Caucasian Phase II trial where the doses from $2.5 \mathrm{mg}$ to $10 \mathrm{mg}$ were tested [5]. The first purpose of this analysis was to characterize the PK and PK/DPP-4 inhibition relationship of linagliptin in Japanese patients with T2DM using a population pharmacokinetic/pharmacodynamic (PK/PD) model. The second purpose of the model development was to simulate the plasma DPP-4 inhibition-time course for Japanese patients receiving $5 \mathrm{mg}$ linagliptin once daily to support the linagliptin dose selection in Japanese patients with T2DM.

\section{METHODS}

\section{Patient population}

In a Phase II trial in Japanese patients with T2DM [14], randomized, double-blind, placebo-controlled multiple dose study, 72 Japanese patients with T2DM were assigned to receive oral doses of linagliptin $0.5,2.5$, or $10 \mathrm{mg}$ or placebo (19 patients, 18 patients, 18 patients, or 17 patients) once daily for 28 days. The inclusion criteria of $\mathrm{HbAlc}$ were $\leq 8.5 \%$ for patients treated with $\leq 1$ oral hypoglycemic agents or $\leq 8.0 \%$ for patients treated with 2 oral hypoglycemic agents. 5 clinical sites were involved in this study. In this analysis, all data were supposed to be included in the analysis. However, the data in $0.5 \mathrm{mg}$ dose group were not fitted the assumption of quasi-equilibrium (for details refer to discussion). Therefore, the data from $2.5 \mathrm{mg}$ dose group and $10 \mathrm{mg}$ dose group were included but the data from $0.5 \mathrm{mg}$ dose group were not included in the analysis. The majority of patients were males; only 9 female patients participated in this study. In the $2.5 \mathrm{mg}$ and $10 \mathrm{mg}$ dose group, the mean $( \pm \mathrm{SD})$ fasting plasma glucose levels at baseline was $154.7 \pm 25.1 \mathrm{mg} / \mathrm{dL}$ and $158.4 \pm 28.6$ $\mathrm{mg} / \mathrm{dL}$; the mean $( \pm \mathrm{SD}) \mathrm{HbA} 1 \mathrm{c}$ level at screening was $7.1 \pm 0.5 \%$ and $7.2 \pm 0.9 \%$; the mean (range) age of patients was 60.2 (42-68) years and 59.1 (40-69) 
years, the mean (range) body mass indices were 26.0 (19.7-33.3) $\mathrm{kg} / \mathrm{m}^{2}$ and 23.8 (18.4-34.4) $\mathrm{kg} / \mathrm{m}^{2}$, respectively. Patients were excluded if they have a relevant history of hepatic, renal, neurologic, cardiovascular, gastrointestinal, metabolic, or hormonal disorders; hyperlipidemia; or hypertension. Individual antidiabetic treatment was discontinued 14 days prior to the first drug administration.

In the result, the statistically significant changes of fasting plasma glucose from baseline of 13.6 $(p<0.05)$ and $25.0(p<0.01) \mathrm{mg} / \mathrm{dL}$ were observed for the 2.5 , and $10 \mathrm{mg}$ dose groups, respectively, whereas fasting plasma glucose level in the placebo group remained almost unchanged relative to baseline level $(3.2 \mathrm{mg} / \mathrm{dL})$.

\section{Study design}

This trial was a randomized, placebo-controlled double-blind multiple-dose study with a parallel group design. Patients received either placebo or 0.5 , 2.5 , or $10 \mathrm{mg}$ of linagliptin as a tablet once daily for 28 days after an overnight fasting. Plasma samples were collected after the first and the last administration of linagliptin, and one trough sample was collected on day 14 (Table 1) for the linagliptin plasma concentration and DPP-4 inhibition. As linagliptin has a very long terminal half-life, plasma samples for concentration and for DPP-4 inhibition were collected until 15 days after the last administration of linagliptin.

The study protocol was reviewed and approved by the ethics committees or institutional review board at each study center. The study was conducted in compliance with the ethical standards established by the Declaration of Helsinki at the time the study was initiated [15] and in accordance with the International Conference on Harmonisation: Harmonised Tripartite Guideline for Good Clinical Practice and the Japanese Good Clinical Practice regulations [16].

\section{Analytical assays}

Linagliptin

Total (bound plus unbound) linagliptin plasma concentrations were determined by a validated high performance liquid chromatography coupled to tandem mass spectrometry (HPLC-MS/MS) at the Department of Bioanalytical Services, Covance Laboratories Ltd., Harrogate, UK as previously described [14]. In brief, plasma was obtained from EDTA blood and measured, undiluted, using $\left[{ }^{13} \mathrm{C}_{3}\right]$ lingliptin as an internal standard. In this study the linear range of concentrations was $0.100 \mathrm{nmol} / \mathrm{L}$ to $100 \mathrm{nmol} / \mathrm{L}$.

\section{DPP-4 inhibition}

DPP-4 activity was analysed by using a semiquantitative enzyme activity assay with fluorescence detection at the Institut für Klinische Forschung und Entwicklung GmbH, Mainz, Germany as previously described [14]. In brief, alanine-proline-7-amido-4-trifluoro-methyl-

coumarin was added to plasma samples, and DPP-4induced cleavage of the substrate to the fluorescent product 7-amino-4-trifluoro-methylcoumarin was then measured as relative fluorescence units (RFU). DPP-4 inhibition was calculated as follows:

DPP-4 inhibition [\%] = 100-(DPP-4 activity/DPP-4 activity at baseline)*100.

\section{Population Pharmacokinetics and Pharmacodynamics analysis}

For nonlinear mixed effects modeling NONMEM, version $\mathrm{V}$ level 1.1, NM-TRAN version III level 1.1, and PREDPP version IV level 1.1 (ICON Development solution, USA) [17] is the standard software. The first-order conditional estimation with interaction method (FOCE-INTERACTION) and the ADVAN 6 (general nonlinear kinetics) subroutine were used to estimate the typical population parameters, random inter-individual variability (IIV) on these parameters, and residual variability between observed and individually predicted plasma concentrations or DPP-4 inhibitions. Graphical visualization software (e.g., SAS 9.2 (SAS institute Inc., USA), Sigmaplot version 10.0 (Systat Software Inc., USA)) was used in addition to Xpose $\mathrm{v} 4 \mathrm{http}: / / x p o s e$. sourceforge.net

\begin{tabular}{ll}
\hline \multicolumn{2}{l}{ Table 1. Plasma sampling points } \\
\hline Day & Time \\
\hline 1 & Before and 0:30h, 1h, 1:30h, 2h, 3h, 4h, 6h, 8h, and 12h after the first administration \\
2,14 & Before linagliptin administration \\
28 to 43 & Six h before the last administration, before, 0:30h, 1h, 1:30h, 2h, 3h, 4h, 6h, 8h, 12h, 24h, 48h, \\
& $120 \mathrm{~h}, 168 \mathrm{~h}, 240 \mathrm{~h}, 312 \mathrm{~h}$, and 360h after the last administration \\
\hline
\end{tabular}


Throughout model development, logtransformed linagliptin concentration data were used. Drug concentrations below the limit of quantification were not implemented into the data set except when measured during the lag time, in which case they were implemented and set to zero.

Model selection was guided by the objective function value (OBJF), the graphical goodness-of-fit analysis, the precision of parameter estimates as reported by the relative standard error obtained from NONMEM. For nested models differing in 1 single parameter, a drop of at least 3.84 in the OBJF (corresponding to $\mathrm{p}<0.05$ for 1-parameter difference, assuming $\chi^{2}$ distribution) was regarded as significant.

\section{Pharmacokinetic model}

As mentioned above, the nonlinear pharmacokinetics of linagliptin can be explained predominantly by a high affinity, low capacity binding to its target enzyme DPP-4, which is readily saturated at therapeutically relevant concentration. Therefore, in a previous analysis in non-Japanese patients with T2DM, this non-linear pharmacokinetics of linagliptin was described using a 2-compartment model with concentrationdependent protein binding in the central and the peripheral compartment (Figure 1) [18].

In this clinical Phase II trial in Japanese patients [14], the pharmacokinetic characteristics of linagliptin (i.e., nonlinear pharmacokinetics, a long terminal half-life, which is not dominant, and low urinary excretion) and the correlation between linagliptin plasma concentration and DPP-4 inhibition were consistent with those of the previous trials in non-Japanese patients [19].
Thus, the previous model structure developed for Caucasian patients accounting for the targetmediated drug disposition was used as starting point for the current analysis of the PK in Japanese patients. IIV was modeled using exponential random effect models, i.e. individual parameters were assumed to have a log-normal distribution around the typical parameter estimates (THETA, $\theta$ ) and variance (OMEGA, $\left.\omega^{2}\right)$. The residual variability was modeled using an additive residual variability model for the log-transformed linagliptin plasma concentrations which approximately corresponds to a proportional error model using untransformed data.

\section{Pharmacokinetic/Pharmacodynamic model}

DPP-4 inhibition was well correlated with total linagliptin plasma concentration by a sigmoid $\mathrm{E}_{\max }$ model [14]. Therefore, a sigmoid $\mathrm{E}_{\max }$ model using total linagliptin concentration was tested in this population analysis as well. In addition, a semimechanistic model was investigated relating the DPP-4 inhibition to the model calculated DPP-4 occupancy (i.e., percentage of DPP-4 molecules bound/inhibited by linagliptin). This model has already been used to describe the relationship between linagliptin pharmacokinetics and DPP-4 inhibition as previously described [18]. It is based on Clark's occupancy theory which states that occupancy is equal to the effect divided by the maximum effect. Thus, the model assumes a linear relationship between plasma DPP-4 inhibition and plasma DPP-4 occupancy with linagliptin. The more linagliptin is bound to DPP-4, the more DPP-4 activity is inhibited until all DPP-4 molecules are blocked by linagliptin and the maximal effect is reached. This is described by the following equation:

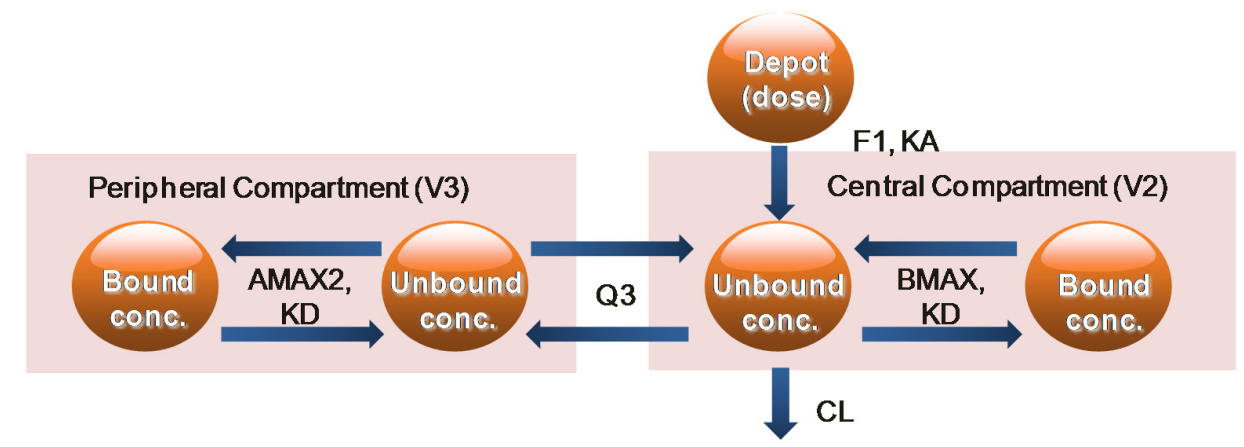

Figure 1. Structure of population PK model

F1: bioavailability, BMAX: concentration of binding sites in the central compartment, Q3: intercompartmental clearance between central and peripheral compartment, AMAX2: amount of binding sites in the peripheral compartment, KA: absorption rate constant, KD: affinity constant, V2: central volume of distribution, V3: peripheral volume of distribution, CL: clearance. 


$$
\text { DPP-4 inhibition }=\mathrm{E}_{\max } * \frac{\mathrm{C}_{\mathrm{b}}}{\mathrm{BMAX}}
$$

$E_{\max }$ : maximal effect

$\mathrm{C}_{\mathrm{b}} / \mathrm{BMAX}$ : percentage of DPP-4 molecules bound/inhibited by linagliptin calculated by PK model

IIV was modeled with an exponential random effect model, i.e., individual parameters were assumed to have log-normal distribution around the typical parameters estimates (THETA, $\theta$ ) and variance $\left(\right.$ OMEGA, $\left.\omega^{2}\right)$. DPP-4 inhibition data were untransformed and the residual variability was considered to be lower when DPP-4 inhibition was high than when DPP-4 inhibition was low. Therefore, the residual variability model was described using the following equation:

$$
\mathrm{Y}=\hat{\mathrm{Y}}+(100-\hat{\mathrm{Y}}) * \varepsilon
$$

where Y represents the observation (i.e. DPP-4 inhibition), $\hat{Y}$ represents the individual predicted concentration and $\varepsilon$ are symmetrically distributed, zero-mean random variables with variance $\left(\sigma^{2}\right)$.

\section{Model evaluation}

For the evaluation of the final population PK/PD model, a visual predictive check (VPC) [20,21] was performed. For pharmacokinetics, the concentrationtime profiles were simulated with 1000 subjects per dose group using the final model parameters. The median and the $5^{\text {th }}$ and $95^{\text {th }}$ percentiles of the simulated concentrations were calculated per dose group, and the observed concentrations were overlaid. The model describes the data sufficiently if most of the observed data are within the $5^{\text {th }}$ to $95^{\text {th }}$ percentiles interval and equally distributed around the median. The pharmacodynamic part of the population PK/PD model was evaluated accordingly.

\section{Simulation}

The objective of the simulation was to predict the DPP-4 inhibition-time profile of the following dose groups, $2.5 \mathrm{mg}, 5 \mathrm{mg}$, and $10 \mathrm{mg}$ linagliptin once daily, in Japanese patients with T2DM. The final PK/PD model was used for this simulation. The DPP-4 inhibition-time profiles at steady state were simulated 1000 times with 200 patients per dose group $(2.5,5,10 \mathrm{mg}$ once daily administration) using the final PK/PD model. The median profiles and $90 \%$ prediction intervals were calculated for the 1000 medians at each timepoints, which were calculated for each dose group in each simulated trial.

\section{RESULTS}

In the $2.5 \mathrm{mg}$ and $10 \mathrm{mg}$ dose group, 498 and 520 plasma concentrations were available for Pharmacokinetic evaluations, 520 and 538 DPP-4 inhibition observations for pharmacodynamic evaluation, respectively (Table 2).

\section{Model development \\ Pharmacokinetic model}

In a previous analysis in non-Japanese patients [18], the pharmacokinetics of linagliptin was described using a 2-compartment model with concentrationdependent protein binding in the central and the peripheral compartment. This structural model was applied to this population analysis of linagliptin in Japanese patients with T2DM.

\begin{tabular}{|c|c|c|c|c|c|c|c|}
\hline \multirow{2}{*}{$\begin{array}{l}\text { Linagliptin } \\
{[\mathrm{mg}]}\end{array}$} & \multirow{2}{*}{$\begin{array}{l}\text { Number } \\
\text { of } \\
\text { patients }\end{array}$} & \multicolumn{3}{|c|}{ Plasma concentrations } & \multicolumn{3}{|c|}{ DPP-4 inhibition } \\
\hline & & $\begin{array}{l}\text { Total } \\
\text { sample }^{\text {a) }}\end{array}$ & Excluded $^{\text {b) }}$ & $\begin{array}{l}\text { Used for } \\
\text { analysis }\end{array}$ & $\begin{array}{l}\text { Total } \\
\text { sample }\end{array}$ & Excluded $^{\text {b) }}$ & $\begin{array}{l}\text { Used for } \\
\text { analysis }\end{array}$ \\
\hline 0.5 & 19 & 533 & 4 & 529 & 552 & 4 & 548 \\
\hline 2.5 & 18 & 501 & 3 & 498 & 523 & 3 & 520 \\
\hline 10 & 18 & 522 & 2 & 520 & 540 & 2 & 538 \\
\hline Total & 55 & 1556 & 9 & 1547 & 1615 & 9 & 1606 \\
\hline
\end{tabular}

Table 2. Number of data for $P K / P D$ analysis

a) BLQ samples not included in the table. 4 BLQ (1 patient in the $2.5 \mathrm{mg}$ dose group, $>168 \mathrm{~h}$ after the last administration),

b) excluded due to the protocol violation (e.g., medication error, or incorrect plasma sampling). 
Initially, all three available doses of linagliptin in Japanese patients, i.e. $0.5,2.5$ and $10 \mathrm{mg}$ linagliptin were used for model building. However, applying the structural model of the previously developed target-mediated drug disposition model resulted in dose-dependent estimates for F1, V2/F1, BMAX. This may be an indication that the assumption of quasi-equilibrium cannot be applied for the $0.5 \mathrm{mg}$ dose group (for details refer to discussion part). As the main aim of the analysis was to predict DPP-4 inhibition in the $5 \mathrm{mg}$ linagliptin dose, a model with dose-dependent parameter estimates was inappropriate. When the data of the $0.5 \mathrm{mg}$ dose group were excluded, the parameters of the target-mediated drug disposition model were well estimated without dose-dependency. To avoid dose dependence of model parameters, and as the main interest was the dose range between 2.5 and 10 $\mathrm{mg}$, the $0.5 \mathrm{mg}$ dose group data were excluded for further model development.

IIV was implemented on F1, KA, CL/F1 and BMAX. The IIV was estimated to be low to high (14.2 to $73.6 \%$ ). OMEGA matrix was investigated using a full OMEGA block and a correlation was found between $\mathrm{BMAX}$ and $\mathrm{CL} / \mathrm{F} 1 \quad(\mathrm{R}=0.837)$. However, as the PK model with a OMEGA block between BMAX and CL/F1 overestimated the variability, the OMEGA block between BMAX and $\mathrm{CL} / \mathrm{F} 1$ was not implemented in the final model. The residual variability, modeled using a proportional variability model, was moderate (27.0\%). All typical parameters except Q3 and AMAX2/F1 were estimated with good precision (standard errors ranging from 10 to $30 \%$ (Table 3 )).

The GOF plots of the final model showed that the model performed adequately, except for a slight under-prediction at higher concentrations (Figure 2).

\section{Pharmacokinetic/Pharmacodynamic model}

To describe the relationship between linagliptin pharmacokinetics and DPP-4 inhibition, a sigmoid $\mathrm{E}_{\max }$ model using the total linagliptin plasma concentrations and a model relating the modelpredicted DPP-4 occupancy with linagliptin to the DPP-4 inhibition (occupancy model) were tested. As the sigmoid $\mathrm{E}_{\max }$ model and the occupancy model were not nested, the OBJF could not be used for model comparison. The occupancy model was chosen as the final model because of the following reasons: (1) the occupancy model is more mechanistic and in line with the pharmacology effect of linagliptin, (2) population predictions and individual predictions in the occupancy model better predicted DPP- 4 inhibition less than $40 \%$ compared to the sigmoid $E_{\max }$ model, (3) based on a VPC, the occupancy model was superior to the sigmoid $\mathrm{E}_{\max }$ model as the $90 \%$ prediction interval was wide in the sigmoid $\mathrm{E}_{\max }$ model (not shown).

The residual variability was lower for nearmaximal inhibitions, compared to lower inhibitions. This was reflected by using the residual variability model described in method parts. The residual variability was moderate $(20.1 \%)$.

The IIV on $\mathrm{E}_{\max }$ was tested but it was very low $(<3 \%)$. Therefore, only the IIV on BMAX was implemented into the final PK/PD model. $\mathrm{E}_{\max }$ was estimated with a good precision (standard error was less than $1 \%$ (Table 3 )).

In general, the GOF plots for DPP-4 inhibition in Figure 2 showed that the model performed adequately.

\section{Model evaluation}

For evaluation, a VPC was performed by simulating the data from this trial 1000 times. In the PK model, the $\mathrm{C}_{\max }$ was slightly underpredicted for the $10 \mathrm{mg}$ dose group and the variability of linagliptin plasma concentration was overpredicted for the $2.5 \mathrm{mg}$ dose group after both the first dose and the last dose administration. However, the simulated median was close to the observed median (Figure 3A). Also in the PD model, the predicted DPP-4 inhibition showed good agreement with the observed DPP-4 inhibition for both doses (Figure 3B).

\section{Simulation}

The final population PK/PD model was used for simulating the steady-state DPP-4 inhibition-time profile after administration of $2.5,5$ and $10 \mathrm{mg}$ linagliptin once daily. Figure 4 shows the median DPP-4 inhibition and the 90\% prediction intervals of 1000 simulated studies with 200 patients per dose group for the three different dose groups. In the 5 $\mathrm{mg}$ and $10 \mathrm{mg}$ dose groups, the simulated median DPP-4 inhibition was $\geq 80 \%$ over 24 hours at steady state (Figure 4). The median of DPP-4 inhibition at 24 hours after the last administration $\left(\mathrm{E}_{24, \mathrm{ss}}\right)$ were $84.2 \%$ and $87.7 \%$ in the $5 \mathrm{mg}$ and $10 \mathrm{mg}$ dose groups, respectively. On the other hand, in the $2.5 \mathrm{mg}$ dose group, $\geq 80 \%$ DPP-4 inhibition could not be maintained over 24 hours and $\mathrm{E}_{24, \mathrm{ss}}$ was less than $80 \%(79.2 \%)$.

\section{DISCUSSION}

This article describes a comprehensive investigation of the population PK/PD of linagliptin in Japanese patients with T2DM. PK/PD evaluation was 
performed using the nonlinear mixed effect modeling program NONMEM, in conjunction with graphical visualization methods.

The nonlinear pharmacokinetics of linagliptin in Japanese patients was described by a 2-compartment model assuming concentration-dependent binding to DPP-4 in the central and the peripheral compartments. The model structure reflects the current knowledge about linagliptin's disposition and is in line with the result of in vitro and preclinical experiments $[9,10]$. Previously, the PK model assuming concentration-dependent protein binding was successfully applied to describe linagliptin's nonlinear pharmacokinetics in nonJapanese patients [18].

Linagliptin shows an apparent nonlinear pharmacokinetics in the therapeutic dose range, although the other DPP-4 inhibitors (sitagliptin [22], saxagliptin [23], vildagliptin [24], alogliptin [25]) exhibit linear pharmacokinetics. This might be explained by the higher affinity of linagliptin to DPP-4 compared with other DPP-4 inhibitors. An in vitro study comparing the $\mathrm{IC}_{50}$ values to $\mathrm{DPP}-4$ activity of several DPP-4 inhibitors showed that $\mathrm{IC}_{50}$ value of linagliptin was much lower than those of the other DPP-4 inhibitors (linagliptin: approximately 1 nmol/L, sitagliptin: $19 \mathrm{nmol} / \mathrm{L}$, alogliptin: $24 \mathrm{nmol} / \mathrm{L}$, saxagliptin:50 nmol/L, vildagliptin: $63 \mathrm{nmol} / \mathrm{L}$ ) [26].

In addition, the dissociation rate from the DPP4 was lower in linagliptin than in vildagliptin [26]. The higher affinity of linagliptin to its target (DPP4) and slow dissociation from the target compared with the other DPP-4 inhibitors result in a unique target-mediated drug disposition.

\section{Pharmacokinetics}

The final model was based on linagliptin plasma concentrations after administration of 2.5 and $10 \mathrm{mg}$ linagliptin. Including linagliptin plasma concentrations after administration of $0.5 \mathrm{mg}$ linagliptin resulted in dose-dependent parameter estimates. As the main aim of the analysis was to predict DPP-4 inhibition in the $5 \mathrm{mg}$ linagliptin dose, a model with dose-dependent parameter estimates was inappropriate.

A possible reason for the model misspecification in the $0.5 \mathrm{mg}$ dose group might be that the applied model assumes quasi-equilibrium conditions for the protein binding process [27]. This assumption can only be made when the ligand concentration (i.e. linagliptin) exceeds the concentration of the binding partner (i.e. DPP-4). In the case of the $0.5 \mathrm{mg}$ dose group, the plasma concentration was below the plasma DPP-4 concentration predicted (BMAX)
(Figure 5). This may be an indication that the assumption of quasi-equilibrium cannot be used for the $0.5 \mathrm{mg}$ dose group. A target-mediated drug disposition model without the assumption of quasiequilibrium was tested to investigate whether the linagliptin plasma concentration-time profile in the $0.5 \mathrm{mg}$ dose group could be described well or not, however, this model did not converge successfully due to its complexity. Therefore, in this analysis, a target-mediated drug disposition model with the assumption of quasi-equilibrium was applied to the data in 2.5 and $10 \mathrm{mg}$ dose group and the data of the $0.5 \mathrm{mg}$ dose group were not used for analysis.

In the final population PK/PD model, $\mathrm{C}_{\max }$ was under predicted in the $10 \mathrm{mg}$ dose group. However, this underprediction was not important for the prediction of DPP-4 inhibition by the final PK/PD model, because the range around these peak concentrations ( $>10 \mathrm{nmol} / \mathrm{L}$ ) were still high enough to achieve the maximum effect in DPP-4 inhibition [14].

The model-estimated dissociation constant for the binding of linagliptin to DPP-4 was $0.108 \mathrm{nmol} / \mathrm{L}$ and is thus within the expected range from the dissociation constant obtained in vitro from plasma samples using equilibrium dialysis $(1 / \mathrm{Ki}=0.05$ $\mathrm{nmol} / \mathrm{L}$ ) [9]. The DPP-4 concentration estimated by the model (BMAX), $6.07 \mathrm{nmol} / \mathrm{L}$, was in the physiological range expected for the DPP-4 concentration in plasma $[26,28,29,30]$.

\section{Simulation}

The main objective of this analysis was to predict the DPP-4 inhibition-time profile of the $5 \mathrm{mg}$ linagliptin dose group, because the approved dose of $5 \mathrm{mg}$ once daily was not tested in a clinical Phase II trial in Japanese patients with T2DM [14]. The steady state DPP-4 inhibition after administration of $5 \mathrm{mg}$ linagliptin once daily was simulated using the final population PK/PD model (Figure 4). The median values of $\mathrm{E}_{24, \mathrm{ss}}$ were predicted to be $79.2 \%$ for 2.5 $\mathrm{mg}, 84.2 \%$ for $5 \mathrm{mg}$, and $87.7 \%$ for $10 \mathrm{mg}$. The actual observed $\mathrm{E}_{24, \mathrm{ss}}$ values were $77.8 \%$ for $2.5 \mathrm{mg}$, and $89.7 \%$ for $10 \mathrm{mg}$ in Japanese patients with T2DM [14] and $76.8 \%$ for $2.5 \mathrm{mg}, 84.8 \%$ for $5 \mathrm{mg}$, and $89.1 \%$ for $10 \mathrm{mg}$ in non-Japanese patients with T2DM [5].

Thus, no apparent difference was observed between the simulated and the actual $\mathrm{E}_{24, \mathrm{ss}}$ value.

The simulations suggest that the administration of $5 \mathrm{mg}$ and $10 \mathrm{mg}$ linagliptin lead to $\geq 80 \%$ DPP-4 inhibition throughout 24 hours at steady state in Japanese patients with T2DM. In contrast, the administration of $2.5 \mathrm{mg}$ linagliptin could not 
maintain $\geq 80 \%$ DPP-4 inhibition throughout 24 hours at steady state in both, the simulation in this analysis and the actual data in the clinical trial in Japanese and non-Japanese patients with T2DM [5, 14]. The literature data in rodent models showed that $\geq 80 \%$ DPP-4 inhibition is related to the nearmaximum effect on glucose lowering [7, 8, 31]. Meanwhile there is also clinical data available that confirm this relationship:

In the current Phase II trial in Japanese patients with T2DM [14], the mean change from baseline of fasting plasma glucose (mean $( \pm \mathrm{SD}))$ after 4 weeks was indeed lower in the 0.5 and $2.5 \mathrm{mg}$ dose group than in the $10 \mathrm{mg}$ dose group $(0.5 \mathrm{mg}:-11.5( \pm 8.3)$ $\mathrm{mg} / \mathrm{dL}, 2.5 \mathrm{mg}:-13.6( \pm 15.2) \mathrm{mg} / \mathrm{dL}, 10 \mathrm{mg}:-25.0$ $( \pm 12.3) \mathrm{mg} / \mathrm{dL})$. And, in a Phase III trial in Japanese patients with T2DM [12], the administration of linagliptin $5 \mathrm{mg}$ once daily, which is the approved dose, elicited reductions in $\mathrm{HbAlc}$ that were significantly greater than the changes achieved by either placebo at week 12 or voglibose at week 26.

The inclusion criteria of $\mathrm{HbAl} \mathrm{c}$ in this study was determined to be $7.0-10.0 \%$ in the patients previously untreated with oral hypoglycemic agents or $\mathrm{HbA} 1 \mathrm{c} 7.0-9.0 \%$ at screening and $7.0-10.0 \%$ after washout in those already receiving 1 or 2 oral hypoglycemic agents for $\geq 10$ weeks. Also this reduction of $\mathrm{HbAlc}$ was confirmed for vildagliptin: in a Phase II trial in Japanese patients with T2DM [24], $\geq 80 \%$ DPP-4 inhibition throughout treatment period at steady state was consistently achieved by vildagliptin $50 \mathrm{mg}$ twice daily but not by $25 \mathrm{mg}$ twice daily. Consistent with these findings, in a clinical trial in the Japanese patients with T2DM [32], a clinically meaningful reduction of $\mathrm{HbA} 1 \mathrm{c}$ was only shown by vildagliptin $50 \mathrm{mg}$ twice daily, the approved dose of vildagliptin, but not by vildagliptin $25 \mathrm{mg}$ twice daily.

\begin{tabular}{|c|c|c|c|}
\hline & $\begin{array}{l}\text { Parameter } \\
\text { Estimate }\end{array}$ & SE $(\%)$ & Description \\
\hline F1 & 1 & FIX & Absolute bioavailability \\
\hline $\mathrm{KA}\left[\mathrm{h}^{-1}\right]$ & 1.63 & 22.2 & First order absorption rate constant \\
\hline $\mathrm{CL} / \mathrm{F} 1[\mathrm{~L} / \mathrm{h}]$ & 121 & 15.5 & Apparent clearance \\
\hline $\mathrm{V} 2 / \mathrm{F} 1[\mathrm{~L}]$ & 633 & 12.7 & $\begin{array}{l}\text { Apparent volume of distribution for } \\
\text { central compartment }\end{array}$ \\
\hline $\mathrm{Q} 3 / \mathrm{F} 1[\mathrm{~L} / \mathrm{h}]$ & 73.0 & 68.8 & $\begin{array}{l}\text { Apparent inter-compartmental clearance between } \\
\text { central and peripheral compartment }\end{array}$ \\
\hline $\mathrm{V} 3 / \mathrm{F} 1[\mathrm{~L}]$ & 683 & 14.0 & $\begin{array}{l}\text { Apparent volume of distribution of the peripheral } \\
\text { compartment }\end{array}$ \\
\hline $\mathrm{BMAX}[\mathrm{nmol} / \mathrm{L}]$ & 6.07 & 5.17 & $\begin{array}{l}\text { Concentration of binding sites in the central } \\
\text { compartment }\end{array}$ \\
\hline $\mathrm{KD}[\mathrm{nmol} / \mathrm{L}]$ & 0.108 & 28.5 & Affinity constant of the nonlinear binding \\
\hline AMAX2/F1[nmol] & 534 & 104 & $\begin{array}{l}\text { Apparent amount of binding sites in the peripheral } \\
\text { compartment }\end{array}$ \\
\hline EMAX [\%] & 92.5 & 0.48 & $\begin{array}{l}\text { Maximum inhibition in percentage based on } \\
\text { baseline activity }\end{array}$ \\
\hline \multicolumn{4}{|c|}{ Model parameters: IIV parameters } \\
\hline IIV in F1 [CV\%] & 46.7 & $30.8^{\text {a) }}$ & $\begin{array}{l}\text { Inter-individual variability in the absolute } \\
\text { bioavailability }\end{array}$ \\
\hline IIV in $\mathrm{KA}[\mathrm{CV} \%]$ & 73.6 & $32.5^{\text {a) }}$ & $\begin{array}{l}\text { Inter-individual variability in the absorption rate } \\
\text { constant }\end{array}$ \\
\hline IIV in CL [CV\%] & 68.8 & $25.7^{\text {a) }}$ & Inter-individual variability in the clearance \\
\hline IIV in BMAX [CV\%] & 14.2 & $30.5^{\text {a) }}$ & $\begin{array}{l}\text { Inter-individual variability in the concentration of } \\
\text { binding sites in the central compartment }\end{array}$ \\
\hline \multicolumn{4}{|c|}{ Model parameters: Residual variability } \\
\hline $\begin{array}{l}\text { Proportional residual } \\
\text { variability } \mathrm{PK}[\mathrm{CV} \%]\end{array}$ & 27.0 & $9.96^{b)}$ & \\
\hline $\begin{array}{l}\text { Proportional residual } \\
\text { variability } \mathrm{PD}[\mathrm{CV} \%]\end{array}$ & 20.1 & 14.6 & \\
\hline
\end{tabular}

a) $\mathrm{SE}$ is given on the variance scale

b) SE was derived by coding the residual error using THETAs 


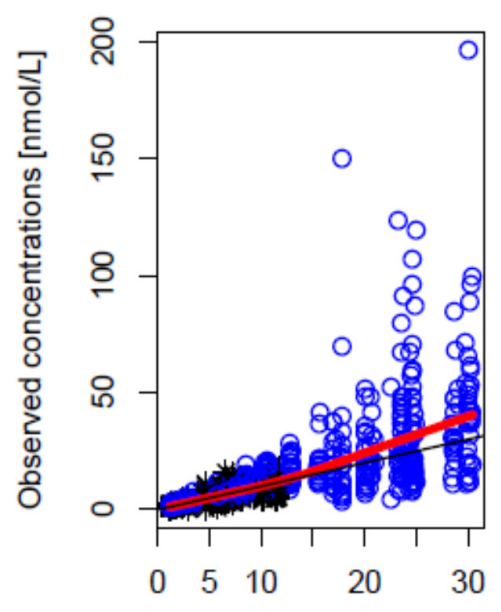

Population predictions [nmol/L]

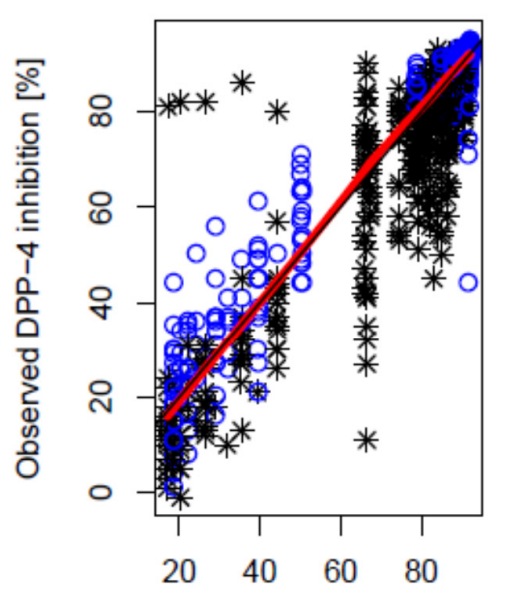

Population predictions [\%]

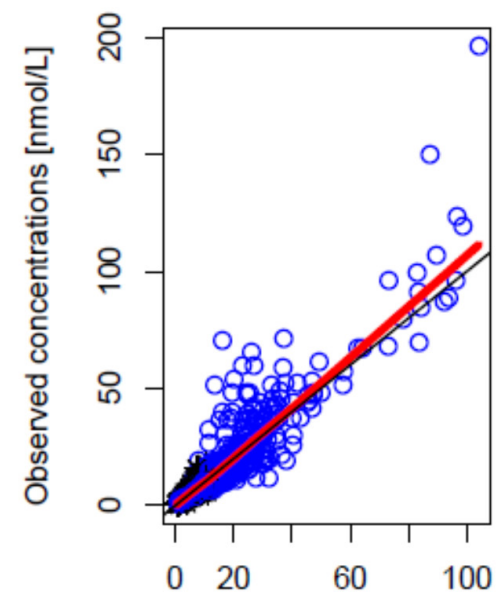

Individual predictions [nmol/L]

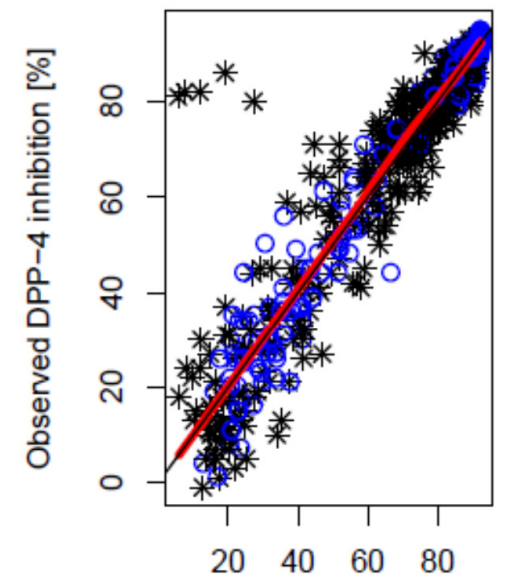

Individual predictions [\%]

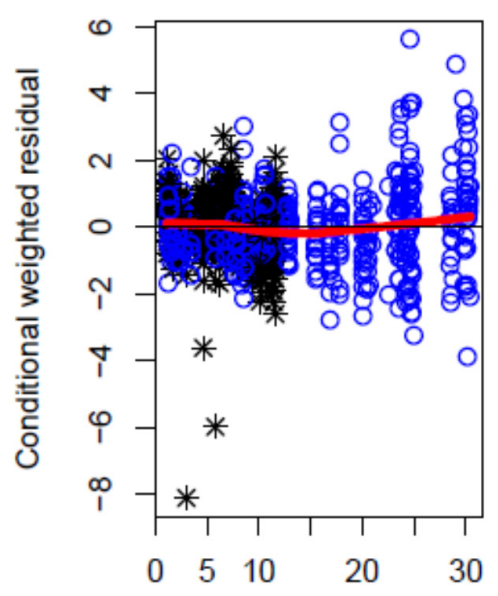

Population predictions [nmol/L]

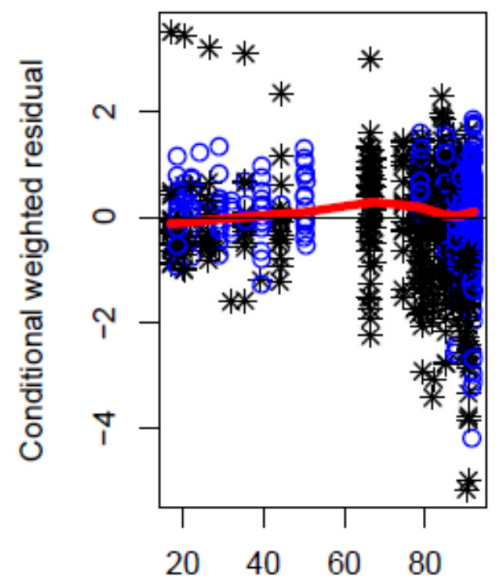

Population predictions [\%]

Figure 2. Goodness-of-fits plots with lines of identity $(2.5 \mathrm{mg}(*), 10 \mathrm{mg}(\mathrm{\circ}))$ : for linagliptin plasma concentration (upper panels) and DPP-4 inhibition (lower panels). Observations versus population predictions (left panels), individual predictions (middle panels), population predictions versus conditional weighted residual (right panels)

For the other DPP-4 inhibitors (sitagliptin, alogliptin), the clinically meaningful reduction in $\mathrm{HbAlc}$ was shown by the approved dose which lead to $\geq 80 \%$ DPP-4 inhibition throughout the treatment period in clinical trial (sitagliptin [33, 34], and alogliptin $[35,36])$. Taken together, $\geq 80 \%$ DPP-4 inhibition throughout treatment period at steady state is considered to be an appropriate pharmacodynamic criterion for full efficacy. Based on this criterion and our model, $5 \mathrm{mg}$ linagliptin once daily would be the optimum dose in Japanese patients with T2DM.

\section{CONCLUSION}

Linagliptin's nonlinear pharmacokinetics and its plasma DPP-4 inhibition in Japanese patients with type 2 diabetes mellitus were well characterized by a target-mediated drug disposition model relating the DPP-4 occupancy with linagliptin to DPP-4 inhibition.

Simulations of the plasma DPP-4 inhibitiontime profile suggest that $5 \mathrm{mg}$ linagliptin once daily is the optimum therapeutic dose for Japanese patients with type 2 diabetes mellitus. 

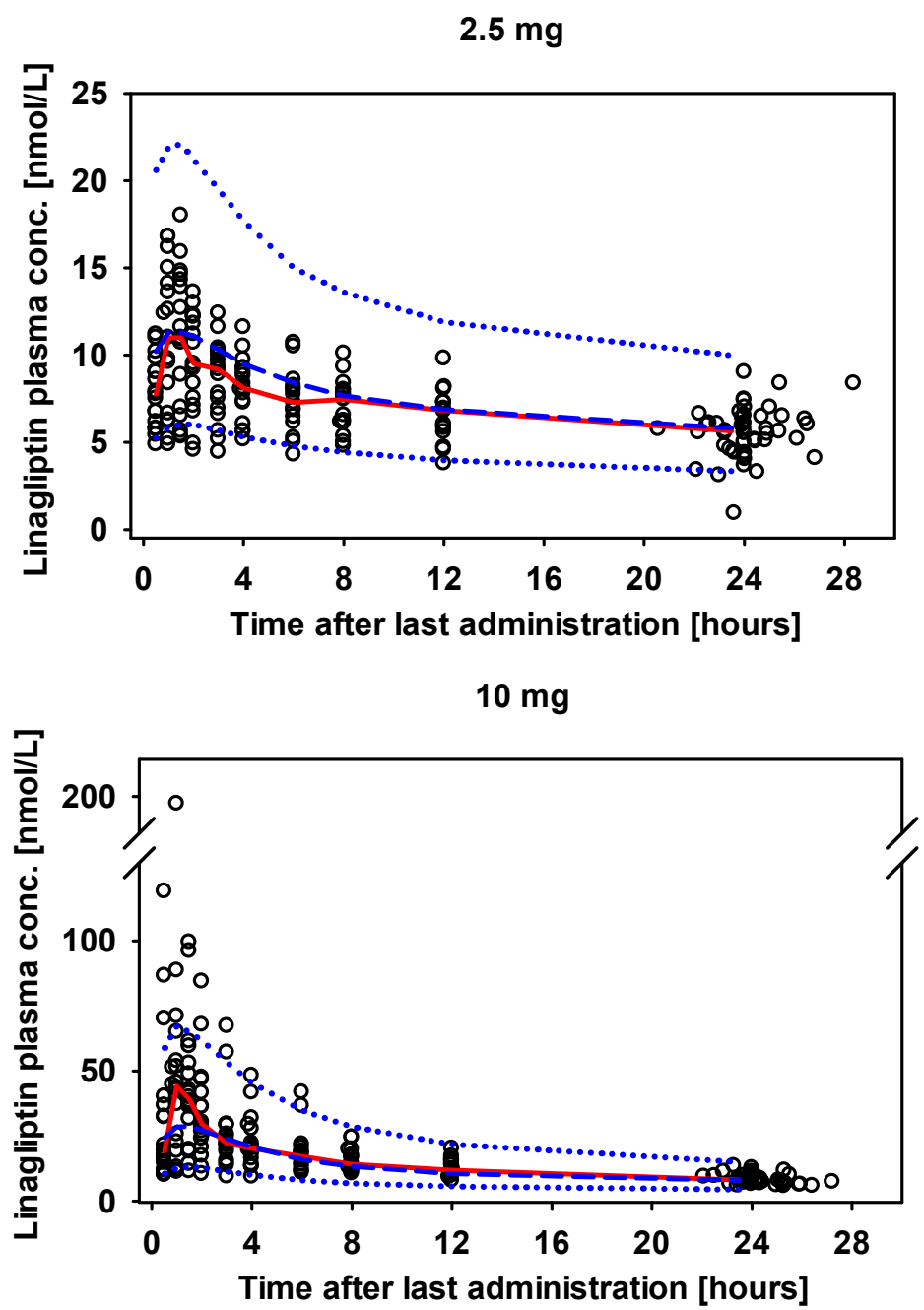

Figure 3A. Visual predictive check for linagliptin plasma concentration (only steady-state profiles shown) 1000 patients per dose group and study were simulated based on the final population PK/PD model. The open circles show the observations and the solid line shows the median of the observations. The dotted lines show the $90 \%$ prediction intervals and the median of the simulated profiles.

\section{DECLARATION}

Boehringer Ingelheim is the study sponsor and manufacturer of linagliptin. YuT, AS, YaT, ST, CF, $\mathrm{SR}$, and AS are employees of Boehringer Ingelheim. MT has declared that he has no conflict of interest.

\section{Abbreviations}

AMAX2: amount of binding sites in the peripheral compartment, AUC: area under the curve, BMAX: concentration of binding sites in the central compartment, $\mathrm{C}_{\mathrm{b}}$ : concentration of linagliptin bound to DPP-4 calculated by PK model, $\mathrm{C}_{\max }$ : maximum plasma concentration, CL: clearance, DPP: dipeptidyl peptidase, $\mathrm{E}_{\max }$ : maximal effect, FOCEINTERACTION: first-order conditional estimation with interaction method, F1: bioavailability, GIP: gastric inhibitory polypeptide, GLP-1: glucagon-like peptide 1, GOF: goodness-of-fit, HbAlc: Hemoglobin A1c, HPLC-MS/MS: high performance liquid chromatography coupled to tandem mass spectrometry, $\mathrm{IC}_{50}$ : half maximal inhibition concentration, IIV: inter-individual variability, KD: affinity constant, NONMEM: non-linear mixed effect modeling, OBJF: objective function value, PK/PD: pharmacokinetic/pharmacodynamic, Q3: intercompartmental clearance between central and peripheral compartment, KA: absorption rate constant, RFU: relative fluorescence units, T2DM: type 2 diabetes mellitus, VPC: visual predictive check, V2: central volume of distribution, V3: peripheral volume of distribution. 

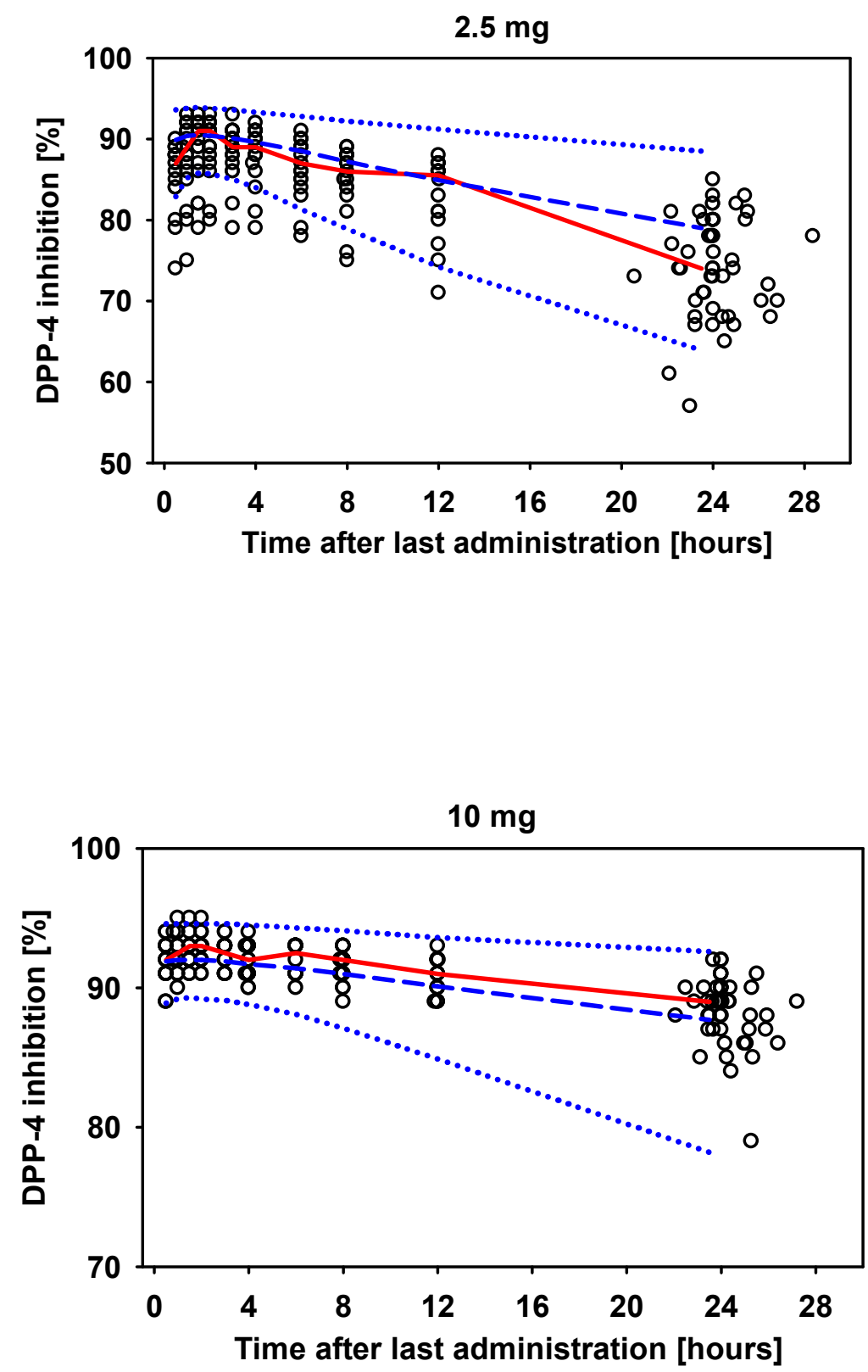

Figure 3B. Visual predictive check for DPP-4 inhibition (only steady-state profiles shown) 


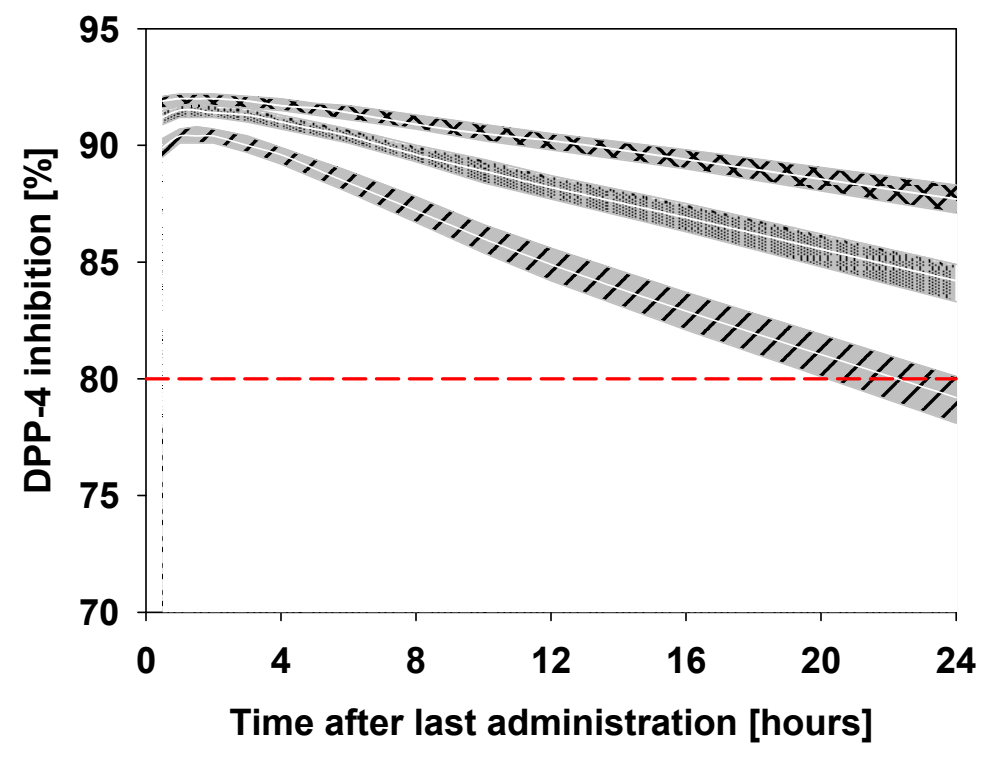

Figure 4. Predicted steady-state DPP-4 inhibition-time profile for patients receiving $2.5 \mathrm{mg}$ ( 12 ), $5 \mathrm{mg}$ ( or $10 \mathrm{mg}$ ( prediction interval (shaded area) are depicted. $80 \%$ inhibition (red-line) is represented.

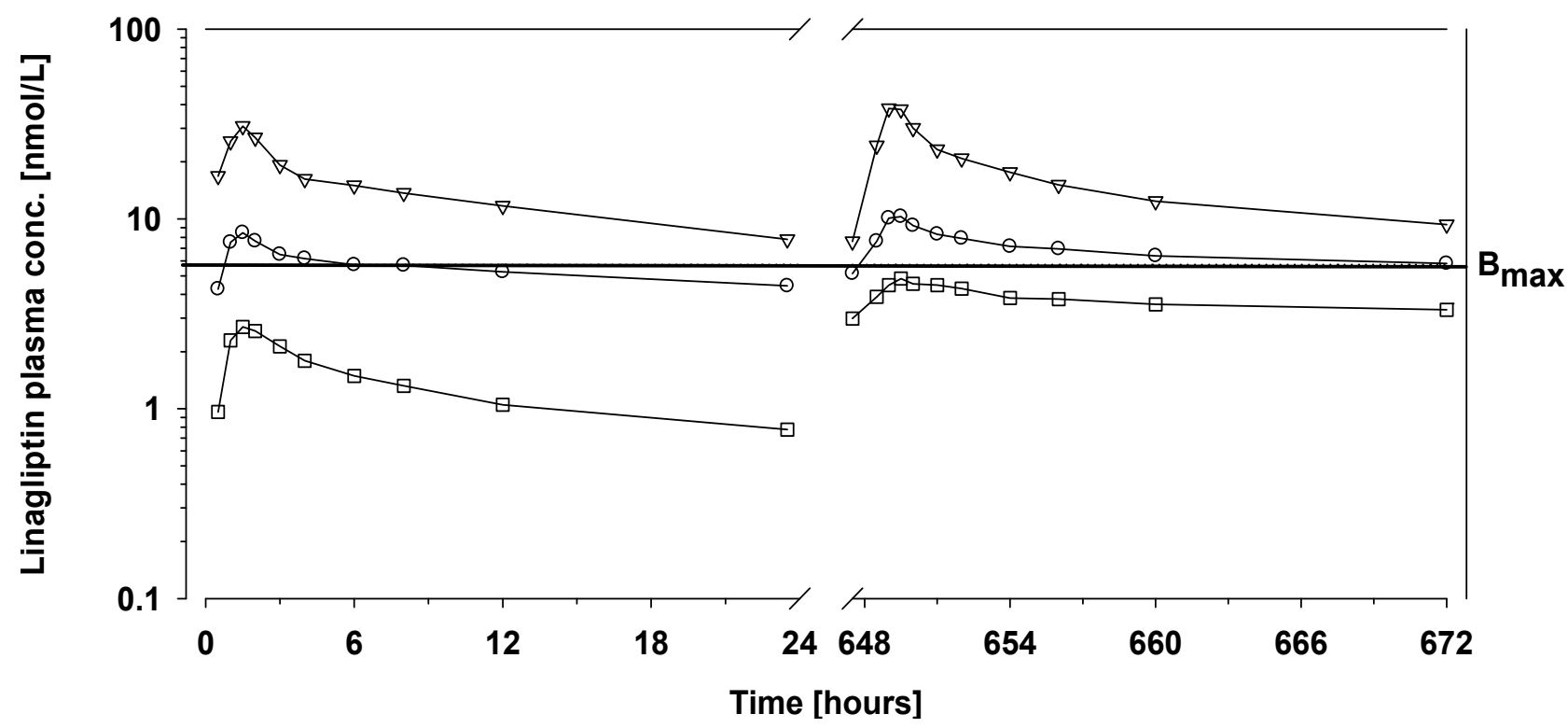

Figure 5. Geometric mean plasma concentration-time profiles of linagliptin $(0.5 \mathrm{mg}(\mathrm{N}=19, \square), 2.5 \mathrm{mg}(\mathrm{N}=18, \circ), 10$ $\mathrm{mg}(\mathrm{N}=18, \nabla))$ with lines of $\mathrm{B}_{\max }$ predicted by model.

\section{REFERENCES}

1. Nauck MA, Bartels E, Orskov C, Ebert R, Creutzfeldt $W$. Additive insulinotropic effects of exogenous synthetic human gastric inhibitory polypeptide and glucagon-like peptide-1-(7-36) amide infused at near-physiological insulinotropic hormone and glucose concentrations. J Clin Endocrinol Metab
1993;76(4):912-917.

2. Meier JJ, Nauck MA. Glucagon-like peptide 1(GLP1) in biology and pathology. Diabetes Metab Res Rev 2005;21:91-117.

3. Farilla L, Bulotta A, Hirshberg B, Calzi SL, Khoury $N$, Noushmehr H, Bertolotto C, Mario U di, Harlan $D M$, Perfetti $R$. Glucagon-like peptide 1 inhibits cell apoptosis and improves glucose responsiveness of 
freshly isolated human islets. Endocrinology 2003;144(12):5149-5158.

4. Toft-Nielsen MB, Damholt MB, Madsbad S, Hilsted LM, Hughes TE, Michelsen BK, Holst JJ. Determinants of the impaired secretion of glucagonlike peptide- 1 in type 2 diabetic patients. J Clin Endocrinol Metab 2001;86(8):3717-3723.

5. Heise T, Graefe-Mody EU, Hüttner $S$, Ring $A$, Trommeshauser D, Dugi KA. Pharmacokinetics, pharmacodynamics and tolerability of multiple oral doses of linagliptin, a dipeptidyl peptidase- 4 inhibitor in male type 2 diabetes patients. Diabetes Obes Metab. 2009 Aug;11(8):786-94.

6. Hüttner S, Graefe-Mody EU, Withopf B, Ring A, Dugi $K A$. Safety, tolerability, pharmacokinetics, and pharmacodynamics of single oral doses of BI 1356, an inhibitor of dipeptidyl peptidase 4, in healthy male volunteers. J Clin Pharmacol. 2008 Oct;48(10):11718.

7. Krishna R, Herman G, Wagner JA. Accelerating drug development using biomarkers: a case study with sitagliptin, a novel DPP4 inhibitor for type 2 diabetes. AAPS J 2008;10(2):401-409.

8. Roy RS, Wu J, Eiermann G, Lyons K, He H, Weber A, Thornberry N. Plasma DPP-4 inhibition by sitagliptin and other DPP-4 inhibitors correlates with and predicts glucose lowering efficacy. 69th Sci Sess of the American Diabetes Association (ADA), New Orleans, 5 - 9 Jun 2009. Diabetes 2009;58(6)(Suppl)

9. Fuchs H, Tillement JP, Urien S, Greischel A, Roth W. Concentration-dependent plasma protein binding of the novel dipeptidyl peptidase 4 inhibitor BI 1356 due to saturable binding to its target in plasma of mice, rats and humans. J Pharm Pharmacol. 2009 Jan;61(1):55-62.

10. Retlich S, Withopf B, Greischel A, Staab A, Jaehde U, Fuchs $H$. Binding to dipeptidyl peptidase-4 determines the disposition of linagliptin (BI 1356)-investigations in DPP-4 deficient and wildtype rats. Biopharm Drug Dispos. 2009 Nov;30(8):422-36.

11. Rowland M, Tozer TN. Clinical pharmacokinetics: concepts and applications (3rd ed.). Philadelphia: Lippincott Williams \& Wilkins; 1995.

12. Kawamori R, Inagaki N, Araki E, Watada H, Hayashi $N$, Horie $Y$, Sarashina A, Gong Y, von Eynatten $M$, Woerle HJ, Dugi KA. Linagliptin monotherapy provides superior glycaemic control versus placebo or voglibose with comparable safety in Japanese patients with type 2 diabetes: a randomized, placebo and active comparator-controlled, double-blind study. Diabetes Obes Metab. 2012 Apr;14(4):348-57.

13. Araki E, Kawamori R, Inagaki N, Watada H, Hayashi $N$, Horie Y, Sarashina A, Thiemann S, von Eynatten $M$, Dugi K, Woerle HJ. Long-term safety of linagliptin monotherapy in Japanese patients with type 2 diabetes. Diabetes Obes Metab. 2012 Nov 19. doi: 10.1111/dom.12039. [Epub ahead of print]

14. Horie $Y$, Kanada S, Watada H, Sarashina A, Taniguchi A, Hayashi N, Graefe-Mody EU, Woerle
HJ, Dugi KA. Pharmacokinetic, pharmacodynamic, and tolerability profiles of the dipeptidyl peptidase- 4 inhibitor linagliptin: a 4-week multicenter, randomized, double-blind, placebo-controlled phase IIa study in Japanese type 2 diabetes patients. Clin Ther. 2011 Jul;33(7):973-89.

15. WMA Declaration of Helsinki-Ethical Principles for Medical Research Involving Human Subjects. 52 ${ }^{\text {nd }}$ WMA General Assembly, Edinburgh, Scotland, October 2000.

16. Ministry of Health, Ordinance No. 28: Standards for the Implementation of Clinical Trials on Pharmaceutical Products. Tokyo, Japan; 1997

17. Beal SL, Sheiner LB, Boeckmann AJ. NONMEM User's Guide-Part I-VII. Ellicott City, MD: Icon Development Solutions

18. Retlich S, Duval V, Graefe-Mody U, Jaehde U, Staab $A$. Impact of target-mediated drug disposition on Linagliptin pharmacokinetics and DPP-4 inhibition in type 2 diabetic patients. J Clin Pharmacol. 2010 Aug;50(8):873-85.

19. Graefe-Mody U, Retlich S, Friedrich C. Clinical pharmacokinetics and pharmacodynamics of linagliptin. Clin Pharmacokinet. 2012 Jul 1;51(7):411-27.

20. Holford N. VPC, the visual predictive checksuperiority to standard diagnostic (Rorschach) plots. 2005; abstract 738, 14. Available at http://www.pagemeeting.org/?abstract $=738$ (last accessed 12 Jan 2013)

21. Karlsson MO, Holford N. A toutrial on visual predictive checks. 2008, 17, Abstract 1434. Available at http://www.page-meeting.org/?abstract=1434 (last accessed 12 Jan 2013)

22. Januvia (sitagliptin) prescribing information. Whitehouse Station (NJ): Merck and Co. Inc., 2012

23. Onglyza (Saxagliptin) prescribing information. Princeton (NJ): Bristol-Myers Squibb Company, 2011

24. He YL, Yamaguchi M, Ito H, Terao S, Sekiguchi K. Pharmacokinetics and pharmacodynamics of vildagliptin in Japanese patients with type 2 diabetes. Int J Clin Pharmacol Ther. 2010 Sep;48(9):582-95.

25. Christopher R, Covington P, Davenport M, Fleck $P$, Mekki QA, Wann ER, Karim A. Pharmacokinetics, pharmacodynamics, and tolerability of single increasing doses of the dipeptidyl peptidase-4 inhibitor alogliptin in healthy male subjects. Clin Ther. 2008 Mar;30(3):513-27

26. Thomas L, Eckhardt M, Langkopf E, Tadayyon M, Himmelsbach F, Mark M. (R)-8-(3-amino-piperidin1-yl)-7-but-2-ynyl-3-methyl-1-(4-methylquinazolin-2-ylmethyl)-3,7-dihydro-purine-2,6dione (BI 1356), a novel xanthine-based dipeptidyl peptidase 4 inhibitor, has a superior potency and longer duration of action compared with other dipeptidyl peptidase-4 inhibitors. J Pharmacol Exp Ther. 2008 Apr;325(1):175-82.

27. Picard-Hagen N, Gayrard V, Alvinerie M, Smeyers H, 
Ricou R, Bousquet-Melou A, Toutain PL. A nonlabeled method to evaluate cortisol production rate by modeling plasma CBG-free cortisol disposition. Am J Physiol 2001;281:E946- E956.

28. Cordero OJ, Ayude D, Nogueira M, RodriguezBerrocal FJ, de la Cadena MP. Preoperative serum CD26 levels: diagnostic efficiency and predictive value for colorectal cancer. Br J Cancer. 2000 Nov;83(9):1139-46.

29. Cuchacovich M, Gatica H, Pizzo SV, GonzalezGronow M. Characterization of human serum dipeptidyl peptidase IV (CD26) and analysis of its autoantibodies in patients with rheumatoid arthritis and other autoimmune diseases. Clin Exp Rheumatol. 2001 Nov-Dec;19(6):673-80.

30. Aso Y, Ozeki N, Terasawa T, Naruse R, Hara K, Suetsugu M, Takabayashi K, Shibazaki M, Haruki K, Morita K, Inukai T. Serum level of soluble CD26/dipeptidyl peptidase-4 (DPP-4) predicts the response to sitagliptin, a DPP-4 inhibitor, in patients with type 2 diabetes controlled inadequately by metformin and/or sulfonylurea. Transl Res. 2012 Jan;159(1):25-31.

31. Kim D, Wang L, Beconi M, Eiermann GJ, Fisher MH, He H, Hickey GJ, Kowalchick JE, Leiting B, Lyons K, Marsilio F, McCann ME, Patel RA, Petrov A, Scapin G, Patel SB, Roy RS, Wu JK, Wyvratt MJ, Zhang BB, Zhu L, Thornberry NA, Weber AE. (2R)-4-oxo-4-[3(trifluoromethyl)-5,6-dihydro[1,2,4]triazolo[4,3a]pyrazin-7(8H)-yl]-1-(2,4,5-trifluorophenyl)butan2-amine: a potent, orally active dipeptidyl peptidase IV inhibitor for the treatment of type 2 diabetes. J
Med Chem. 2005 Jan 13;48(1):141-51.

32. Kikuchi $M$, Abe $N$, Kato $M$, Terao $S$, Mimori $N$, Tachibana $H$. Vildagliptin dose-dependently improves glycemic control in Japanese patients with type 2 diabetes mellitus. Diabetes Res Clin Pract. 2009 Feb;83(2):233-40.

33. Iwamoto $Y$, Taniguchi T, Nonaka K, Okamoto T, Okuyama K, Arjona Ferreira JC, Amatruda J. Doseranging efficacy of sitagliptin, a dipeptidyl peptidase4 inhibitor, in Japanese patients with type 2 diabetes mellitus. Endocr J. 2010;57(5):383-94.

34. Herman GA, Mistry GC, Yi B, Bergman AJ, Wang AQ, Zeng $W$, Chen L, Snyder K, Ruckle JL, Larson PJ, Davies MJ, Langdon RB, Gottesdiener KM, Wagner $J A$. Evaluation of pharmacokinetic parameters and dipeptidyl peptidase-4 inhibition following single doses of sitagliptin in healthy, young Japanese males. Br J Clin Pharmacol. 2011 Mar;71(3):429-36.

35. Covington P, Christopher R, Davenport M, Fleck $P$, Mekki QA, Wann ER, Karim A. Pharmacokinetic, pharmacodynamic, and tolerability profiles of the dipeptidyl peptidase-4 inhibitor alogliptin: a randomized, double-blind, placebo-controlled, multiple-dose study in adult patients with type 2 diabetes. Clin Ther. 2008 Mar;30(3):499-512.

36. Seino Y, Fujita T, Hiroi S, Hirayama M, Kaku K. Efficacy and safety of alogliptin in Japanese patients with type 2 diabetes mellitus: a randomized, doubleblind, dose-ranging comparison with placebo, followed by a long-term extension study. Curr Med Res Opin. 2011 Sep;27(9):1781-92. 